\title{
Afetar e sensibilizar na educação: uma proposta transdisciplinar
}

Solange Martins Oliveira Magalhães

Universidade Federal de Goiás

\section{Resumo}

A proposta complexa e transdisciplinar abre novas perspectivas para o campo educacional. Essas perspectivas procuraram religar o conhecimento à vida, reorientando os processos de formação para que se valorize a constituição de um sujeito sensível e afetivo. A vocação transdisciplinar institui novas práticas pedagógicas formadoras de uma razão-afetivo-sensível, capaz de promover uma visão mais integrada do ser humano. Nesta concepção de educação, o processo ensino-aprendizagem supera o processo lógico e intelectual, torna-se um processo dinâmico, coerente, dialógico e criativo. Promover a proposta transdisciplinar na formação docente passa pela vivência de formar pessoas que tornarão nossa experiência no mundo mais cooperativa, amorosa e solidariamente compreendida.

Palavras-chave: Educação. Afetividade. Sensibilidade. Transdisciplinaridade. Formação docente. 


\section{To affect and sensitize in education: a transdisciplinary proposal}

A complex and transdisciplinary proposal opens new perspectives in the educational field. Such perspectives seek to reconnect knowledge to life, by redirecting educational processes towards encouraging the creation of sensitive and emotional individuals. A transdisciplinary vocation establishes new pedagogical practices, forming an affectivesensitive-reason, capable of promoting a more integrated vision the human being. In this conception of education, the teaching-learning process surpasses the logical and intellectual process and becomes a dynamic, coherent, dialogic and creative process. To promote a transdisciplinary proposition in teacher training means experiencing the act of educating people, who will make our experience in the world more cooperative, loving and solidly understood.

Keywords: Education. Affectivity. Sensitivity. Transdisciplinarity. Teacher training.

\section{Afectar y sensibilizar en la Educación: una propuesta transdisciplinaria}

La propuesta compleja y transdisciplinaria abre nuevas perspectivas para el campo educativo. Esas perspectivas han buscado religar el conocimiento a la vida, reorientando los procesos de la formación de modo que valorice la constitución de un individuo sensible y afectivo. La vocación transdisciplinaria instituye nuevas prácticas pedagógicas formadoras de una razón-afectivo-sensible, capaz de promover una visión más integrada del ser humano. En este concepto de la educación, el proceso enseñanza-aprendizaje sobrepasa el proceso lógico e intelectual, convierténdose en un dinámico, coherente, dialógico y creativo proceso. Promover la propuesta transdisciplinaria en la formación docente pasa por la vivencia de formar gente que hará nuestra experiencia en el mundo entendida como más cooperativa, amorosa y solidaria.

Palabras clave: Educación. Afectividad. Sensibilidad. Transdisciplinaridad. Formación docente. 


\section{Introdução}

Existem momentos na vida em que a questão de saber se podemos pensar diferentemente do que se pensa e perceber diferentemente do que se vê torna-se indispensável para continuarmos a olhar ou a refletir e, supostamente, caminhar. Essa ideia nos impele a questionar: podemos olhar as coisas de forma diferente no contexto educativo? É possível percorrer novos caminhos que nos revelem o que há de bom nas (inter)relaç̃̃es entre o conhecer e a vida?

Talvez o nosso caminhar rumo ao conhecimento pudesse ser menos autoritário, livre do poder e da hierarquia, tornando-se mais leve, sem tantas regras para proteger e administrar o saber; algo assim como o voo de uma borboleta: despretensioso, delicado, sensível. Esta é uma reflexão provocadora, principalmente quando, na condição de professores e professoras, pensamos na sala de aula.

Seríamos capazes de pensar esse diferente? Seríamos capazes de pensar uma educação que destaque a importância da afetividade e da sensibilidade para os processos formativos? Essa educação poderia nos ajudar a superar o modelo de pensamento linear sustentado em nossa sociedade? Afinal, poderíamos permitir a percepção das nuances do voo da borboleta quando temos que perseguir tantos conteúdos, sistematizações e objetivos acadêmicos?

Freire (1996, p. 160) realçou que esta forma de educar representa um "educar fascinante, comovente", que também passa pela possibilidade de admirarmos e celebrarmos a vida; notar sua beleza, sua complexidade e, através da valorização da afetividade e da sensibilidade humanas, mas não exclusivamente por meio delas, perceber que vivemos numa realidade totalmente interconectada, sinergética, sincrônica, portanto viva e ativa.

Freire ainda esclareceu que, para tanto, necessitaríamos estar vivendo num círculo de relacionamento que permitisse a presença de espíritos livres, criativos, libertos da cadeia de comando que assola e conforma nossa educação. Para o autor, “[...] ensinar e aprender não podem dar-se fora da procura, fora da boniteza e da alegria [...] a educação deve ser 'estética e ética'" (Freire,1996, p. 26). Muito provavelmente, precisaríamos também da convicção interior de que podemos rever e superar nossos paradigmas, sempre na busca de soluções viáveis para as difíceis questões humanas (Freire, 1996).

As palavras de Freire tomam concretude quando acreditamos que a forma como os sujeitos vão viver a sua realidade e o modo como a transformam ligam-se, invariavelmente, à educação. Os professores são conhecedores desta verdade, querem transformar a realidade; trabalham para que seus alunos e alunas entendam como o conhecimento pode afetar e influenciar a forma como vivem. Entretanto, a forma como os professores valorizam e articulam os campos dos saberes depende de seus processos formativos. 
Infelizmente, uma educação apoiada em um currículo que pensa a formação de maneira disciplinar dificilmente abrirá espaços para que se possa trabalhar a afetividade e a sensibilidade, mesmo reconhecendo-se a importância desses aspectos para a formação humana.

Ao longo dos anos, tem-se procurado deliberadamente docilizar e conformar o corpo, as emoções, os sentimentos dos sujeitos, investindo-se na busca da uniformidade de lógicas com propósitos de anestesiamento, homogeneização, massificação e controle. Essa ação também incide sobre os processos de socialização promovendo o descuido, a denegação do sensível, da expressão da sensibilidade, da intuição, do afetivo, do senso de compreensão do mítico e do espiritual (Araújo, 2009).

Ao desqualificar e patologizar a expressão e a importância da afetividade e da sensibilidade, a educação deixa de auxiliar o sujeito, como mediadora que é na compreensão efetiva e afetiva do mundo, e sua complexidade. Ao proclamar uma razão isolada e desvinculada da afetividade e da sensibilidade, a educação, além de incidir em processos reducionistas, impede que o educar seja prazeroso, de descobertas, desejos e realizações.

A esse respeito, Deleuze (2007) é incisivo ao afirmar que é uma boa formação que nos torna capazes de inspirar a educação, torná-la fascinante. 0 que fascina interessa e, se interessa, pode despertar entusiasmo e paixão. Essa ideia torna o ato de educar uma aventura e, segundo Deleuze, configura uma conjunção amorosa.

A conjunção amorosa, para Barthes (2005), envolve as escolhas dos conceitos, textos, livros, obras que utilizamos na sala de aula; também implica a forma como sentimos os autores e autoras escolhidos, como nos relacionamos com eles, e como ensinamos a outros essa conjunção amorosa. 0 professor que estabelece a conjunção amorosa é capaz de promover momentos inspiradores que promovem o prazer de aprender, a magia de inspirar mudanças, refletir, reescrever, criar, partilhar, o que nas palavras de Assmann (1998) acaba indicando que o professor possui a capacidade de reencantar a educação.

Falamos de pensar e viver uma educação do mesmo modo que um artista pensa e vive a sua arte. Felizmente, o processo educacional comporta tal atitude, afinal, nos processos de formação devemos dar ênfase aos aspectos cognitivos mas não só, também aos afetivos, pois sabemos que esses aspectos marcam e conferem aos objetos um sentido que acaba determinando a qualidade das aprendizagens dos sujeitos.

Apesar de a escola ser um local onde o compromisso maior que se estabelece é com o processo de construção de conhecimento, as relações afetivas se evidenciam. 0 trabalho pedagógico implica, necessariamente, uma interação entre pessoas, com sentimentos, afetos e sensibilidades. Na ação do professor há um processo amplo de mediação que afeta cada aluno e aluna individualmente e o grupo, e tende a influenciar a aprendizagem destes, marcando decisivamente essas pessoas, bem como seus futuros. 
0 processo ensino-aprendizagem pode apresentar resultados profundamente afetivos, determinando a constituição dos indivíduos de forma duradoura (Luckesi, 1984; Mahoney, 1993; Dantas, 1993; Pereira, 1998; Almeida, 1997; Grotta, 2000; Tassoni, 2000). Práticas educativas permeada por sentimentos de acolhimento, simpatia, cooperação, solidariedade, respeito e apreciação, compreensão, aceitação e valorização do outro não só marcam o desenvolvimento humano, como também a relação do aluno e da aluna com o objeto de conhecimento, a qualidade dos vínculos que se estabelecem entre os sujeitos-sujeitos e entre os sujeitos e os objetos do conhecimento.

Mas como estamos trabalhando a questão da afetividade e da sensibilidade nos cursos de formação de professores e professoras? Essa reflexão tem o objetivo de destacar a importância da constituição de uma razão-afetivo-sensível na tecelagem do existir. Reorienta-se, assim, a formação docente, valorizando-se o sujeito sensível e afetivo.

\section{A afetividade e a formação docente}

Afetar, afeição, vem do latim affectio, que é a maneira de ser, disposição, simpatia, estima. No pensamento filosófico, afeição significa sentimento terno e está ligada ao verbo afetar que, por sua vez, significa exercer uma ação sobre uma coisa ou sobre alguém. No campo da psicologia, afeição designa certo estado da sensibilidade. 0 sensibilizar ou a sensibilidade, que também deriva do latim - sensihilitas -, em um sentido genérico, é a capacidade de sentir, de ser afetado por algo (Japiassú; Marcondes, 2001).

No caso do estudo das emoções, as reflexões apontam para a marcante influência do paradigma simplificador, caracterizado tanto pela pluralidade de teorias e metodologias como pelas poucas articulações e diálogos entre si. A compreensão complexa, inspirada particularmente pela obra de Morin (1998), implica não apenas nas possíveis articulações entre as distintas contribuições, mas, principalmente, na demanda de esforços para que sejam superadas as disjunções clássicas do paradigma ocidental sobre tais conceitos (Morin, 2008; Santos, 1987).

As definições propostas na literatura dos termos afetividade, emoção, afeto e sentimento evidenciam que eles são aparentemente sinônimos. "Afetividade tem sido utilizada com uma significação mais ampla, referindo-se às vivências dos indivíduos e às formas de expressão mais complexas e essencialmente humanas". Refere-se à capacidade, à disposição do ser humano de ser afetado pelo mundo externo e interno por sensações ligadas ao corpo, que podem ser sentidas como agradáveis ou desagradáveis. 0 termo emoção, na maioria das vezes, "encontra-se relacionado ao componente biológico do comportamento humano, referindo-se a uma agitação, uma reação de ordem física" (Leite; Tassoni, 2010, p. 2). 
As emoções, segundo a Teoria das Emoções de Henri Wallon, são a exteriorização da afetividade, um fato fisiológico nos seus componentes humorais e motores e, ao mesmo tempo, um "comportamento social na sua função de adaptação do ser humano ao seu meio". As relações que as emoções tornam possíveis afinam os meios de expressão do ser humano, e fazem deles instrumentos de sociabilidade cada vez mais especializados (Wallon, 1995, p. 143).

Sustentando-se na teoria de Wallon, Mahoney e Almeida (2005) indicam que a emoção seria a exteriorização da afetividade, sua expressão corporal. Portanto, a emoção é profundamente expressiva e mantém um sistema de atitudes como: medo, alegria, raiva, ciúmes, tristeza, com um correspondente postural que libera ou concentra energia com maior ou menor intensidade. A emoção é um instrumento de sociabilidade que, ao expressar uma forma concreta de participação mútua, funde adequadamente as relações interindividuais.

0 sentimento, por sua vez, corresponde à expressão representacional da afetividade, não imprime reações instantâneas como a emoção, pois se opõe à expressão corporal marcada pela presença da emoção. Os sentimentos podem ser expressos pela mímica e pela linguagem, ou seja, pelos recursos de expressão representacionais, o que demonstra que os sentimentos exigem observação e reflexão antes do agir. Isso indica que os sentimentos "traduzem intelectualmente seus motivos e circunstâncias" (Mahoney e Almeida, 2005, p. 11). E, por fim, a paixão revela o aparecimento do autocontrole para dominar as situações, por isso seu efeito procura silenciar a emoção.

Pino (2005, p. 128) tem apresentado que os termos afeto, emoção, sentimento e afetividade referem-se às experiências subjetivas, que revelam a forma como cada sujeito "é afetado pelos acontecimentos da vida ou, melhor, pelo sentido que tais acontecimentos têm para ele". Para o autor, fenômenos afetivos evidenciam como cada acontecimento da vida repercute em cada sujeito, ou seja, como reage e quais serão as suas atitudes diante das pessoas. Dessa forma, o afetivo é uma qualidade das relações humanas e das experiências que elas evocam. Essa qualidade confere ao conjunto da realidade que forma seu contexto (coisas, lugares, situações etc.) um sentido afetivo.

Assim reforça-se a ideia de que os fenômenos afetivos são de natureza subjetiva, mas isso não os torna independentes da ação do meio sociocultural, ao contrário, estão diretamente relacionados com a qualidade das interações entre os sujeitos enquanto experiências vivenciadas.

No campo da educação, Fernandez (1991), Dantas (1992), Snyders (1993), Freire (1996) e Codo e Gazzotti (1999) também se manifestaram em defesa do afeto, afirmando que ele é indispensável na atividade de ensinar, entendendo que as relações entre o ensinoaprendizagem são movidas pelo desejo e pela paixão. Assim sendo, é possível identificar e prever condições afetivas favoráveis que facilitem o processo ensino-aprendizagem. 
Vejamos a proposta de Vygotsky (1998), que sustentou a base explicativa das emoções destacando que durante o desenvolvimento os sujeitos humanos têm emoções primitivas que evoluem para um plano superior - o simbólico, o da significação e do sentido -, que dará lugar a um nível mais complexo de atuação do ser humano, mais consciente e autodeterminado.

Assim como Wallon $(1971 ; 1978)$ em sua psicogênese, Vygotsky também procurou articular o biológico e o social, atribuindo às emoções um papel de primeira grandeza na formação da vida psíquica. A diferença é que em Wallon a emoção é o primeiro e mais forte vínculo entre os indivíduos. As relações que a criança estabelece com o mundo exterior são, desde o início, relações de sociabilidade que promoverão "uma fusão de sensibilidade entre o indivíduo e o seu entourage" (Wallon, 1971, p. 262).

A definição de afetividade e emoções encontra nestas propostas sua concretude: ela assume o caráter social da afetividade (Vygotsky, 1998; Wallon, 1971), assim como uma abordagem de desenvolvimento da afetividade (Wallon, 1971), destacando que "a afetividade e a inteligência constituem um par inseparável na evolução psíquica, pois ambas têm funções bem definidas e, quando integradas, permitem ao sujeito atingir níveis de evolução cada vez mais elevados" (Wallon, 1971, p. 51).

A forma de a afetividade facilitadora se expressar no processo ensino-aprendizagem também exige a existência, a colocação de limites. Tais limites podem facilitar o processo ensino-aprendizagem, garantindo o bem-estar de todos os envolvidos. Isso garante que os limites também são uma expressão de afetividade.

Orientados por essas propostas, já poderíamos mudar o sentido da educação. Ela passaria a gerar nas relações estabelecidas várias possibilidades como: inovar, criar, realizar, promovendo um novo entendimento das coisas que vai do simples ao complexo, e do complexo ao simples.

Entretanto, mesmo destacando-se a importância da afetividade para os processos, formativos ainda não conseguimos formar sujeitos que se transformem continuamente, autotranscendendo, capazes de refletir novos valores e ideais.

Talvez esse seja o desafio transdisciplinar para a educação: afetar e sensibilizar os sujeitos, e nesse processo, cremos, reencantar a educação e os sujeitos, auxiliando-os a desenvolver a capacidade de auto-organizar-se e de estabelecer refletidas relações com o outro, consigo e com a natureza. 


\section{0 desafio transdisciplinar: afetar e sensibilizar nos contextos formativos}

O ser humano, no seu diálogo com o mundo, se mobiliza emocionalmente de diversas formas que remetem à sua história e à própria construção de sua subjetividade. Boa parte de suas experiências e processos emocionais não se esgotam em sua fala, em seus comportamentos, pensamentos; ao contrário, permanecem ativamente atuantes e até determinantes na própria maneira de ser que o sujeito efetiva.

A vocação complexa ${ }^{1}$ e transdisciplinar ${ }^{2}$ pressupõe um sujeito que aceita as intensidades dos seus sentires; entende que a sensibilidade e a afetividade são forças que movem, comovem, desconsertam e inquietam inclusive a própria razão. Não há como retirar o estado afetivo e sensível dos sujeitos, de sua corporeidade, do cotidiano das suas vivências, e muito menos das relações que se estabelecem no contexto educativo.

Para trazer à luz o exemplo desse diálogo, empreendemos uma pesquisa com 45 estudantes da disciplina Sociedade, Cultura e Infância do curso de Pedagogia da Universidade Federal de Goiás no segundo semestre letivo do ano de 2009. Utilizamos a perspectiva qualitativa de pesquisa e os princípios do estudo de caso. A perspectiva ou abordagem qualitativa recobre atualmente um campo transdisciplinar que envolve as ciências humanas e sociais, adota multiparadigmas de análise que podem ser derivados do positivismo, da fenomenologia, da hermenêutica, do marxismo, da teoria crítica e do construtivismo. É uma perspectiva que adota uma metodologia de investigação pautada em (multi)instrumentos para o estudo de um fenômeno situado no local em que ocorre, assim como para interpretar os significados que os sujeitos dão a eles. Pode-se dizer que uma pesquisa qualitativa tende para o estudo de questões delimitadas, locais, apreendendo os sujeitos no ambiente natural em que vivem suas interações interpessoais e sociais, nas quais tecem os significados e constroem a realidade. A abordagem qualitativa permite análises contextualizadas dos fenômenos da realidade social, do conhecimento e do ser humano em sua totalidade (Souza; Magalhães; Guimarães, 2009a; 2009b; 2010).

Para Triviños (1987, p. 133), o estudo de caso "é uma categoria de pesquisa cujo objeto de estudo é uma unidade que se analisa aprofundadamente". 0 autor aponta que

1. A palavra complexo, na sua etimologia quer dizer, entrelaçado, tecido em conjunto. Sobre o pensamento complexo ver Morin (1991).

2. Segundo Nicolescu (2001), o prefixo trans de transdisciplinaridade indica o que está ao mesmo tempo entre as disciplinas, através delas e além de qualquer uma delas, dando uma ideia de transcendência e de inter-relações no mundo e na vida. A transdisciplinaridade está relacionada ao mundo acadêmico, pois se preocupa com aquela parte do mundo real que trata do conhecimento, de sua organização em disciplinas, das superposições e espaços vazios entre elas. 
esse tipo de pesquisa visa atingir a máxima amplitude na descrição, explicação e compreensão do foco em estudo - permite trazer à tona a técnica da triangulação. Esta técnica permite dirigir nosso interesse aos processos e produtos centrados no sujeito: averiguando as percepções do sujeito, mediante entrevistas e questionários, e os comportamentos e ações do sujeito, na observação livre; aos elementos produzidos pelo meio do sujeito: documentos, especificações de sistemas, projetos etc. (Bogdan; Biklen, 1994, p. 891

As observações das atividades propostas e os relatos dos alunos e alunas foram significativos na análise. Aqui relatamos uma atividade pedagógica considerada inovadora pelos estudantes, em função dos resultados obtidos no processo ensino-aprendizagem, pautada nos referenciais da transdisciplinaridade, que teve como conteúdo programático o Plano Nacional de Educação em Direitos Humanos - PNEDH (Brasil, 2008). Na atividade, utilizaram-se os recursos das oficinas pedagógicas de Direitos Humanos, conforme proposto por Candau (1995).

A reflexão sobre os direitos humanos e o PNEDH é frutífera e relevante para a formação docente. No planejamento da atividade tomamos como referência a ementa oficial da disciplina, a partir da qual propusemos estratégias valendo-nos de discussões com os estudantes sobre o percurso das atividades. A disciplina aborda temas relacionados à sociedade, à educação, sua historicidade, bem como aos temas de Educação em Direitos Humanos (EDH), Plano Nacional de Educação em Direitos Humanos (PNEDH, 2008), suas possibilidades transformadoras do contexto educacional.

Foram realizadas discussões ampliadas sobre o assunto, permitindo perspectivas interativas entre os campos disciplinares, além de revisão e suprimento de eventuais temas a serem abordados. Desta forma, oportunizou-se aos sujeitos educandos estabelecerem sensíveis e afetivas interações e atualizações de seus conhecimentos no campo dos direitos humanos, articulando-os à formação docente. Lembramos que o processo transdisciplinar implica uma dinâmica aberta, fundada na solidariedade, no diálogo, no sensível questionamento constante e nas reflexões sobre as ações desenvolvidas no/ com/fora do grupo.

$\mathrm{Na}$ dinâmica da atividade, procurou-se levar em consideração a pluralidade dos participantes, retratando a possibilidade metodológica integradora proposta pelo Projeto do Curso de Pedagogia da Universidade Federal de Goiás. Nele, a formação é concebida como processo de inserção crítica dos sujeitos no universo da cultura, do pensamento, da autonomia, da liberdade, da justiça, da democracia e da solidariedade.

Com o objetivo de trabalhar aspectos ligados a afetividade e sensibilidade dos estudantes, a atividade proposta pautou-se na leitura e análise de texto retirado do livro Educar para a conexão (Silva, 2004). Foram dadas as seguintes orientações: leitura, 
análise e discussão em grupos do texto carta 23, encontrada nos muros de um campo de concentração na Alemanha após a Segunda Guerra Mundial. Para Silva (2004), ela foi escrita por alguém que sofreu com a falta de conexão entre os seres humanos. Vejamos o texto:

Prezado Professor: Sou sobrevivente de um campo de concentração. Meus olhos viram o que nenhum homem deveria ver. Câmaras de gás construídas por engenheiros formados, crianças envenenadas por médicos diplomados, recém nascidos mortos por enfermeiras treinadas, mulheres e bebês fuzilados e queimados por graduados de colégios e Universidades. Assim, tenho minhas suspeitas sobre a Educação. Meu pedido é: ajude seus alunos a tornarem-se humanos. Seus esforços nunca deverão produzir monstros treinados ou psicopatas hábeis. (Silva, 2004, p. 87)

Logo após, foi aberto o debate acerca do conteúdo da carta, suscitando a sensibilidade, a afetividade e a promoção de autoconhecimento, assim como a reflexão sobre a vivência do valor da igualdade em dignidade e direitos para todos. As conclusões a que os grupos chegaram foram apresentadas em formas de oficinas pedagógicas, como proposto por Candau (1995), associadas aos artigos da Declaração Universal de Direitos Humanos - DUDH ${ }^{3}$.

A metodologia utilizada teve o objetivo de maximizar a aprendizagem ao trabalhar com atividades que mobilizam, conjuntamente, as dimensões mentais, emocionais, sensíveis e corporais, tecendo relações tanto horizontais como verticais do conhecimento.

Numa perspectiva transdisciplinar, devemos criar situações de reflexão capazes de maior envolvimento dos sujeitos na construção de significados. Trabalhar a educação com tal visão encanta o aprender e resgata o prazer de aventurar-se no mundo das ideias. Afirmamos isso pois observamos que ao optar pela execução de uma oficina específica - teatral, musical, cordel, dança e poesia - cada grupo de estudantes esforçou-se para sua realização, envolvendo-se efetiva e afetivamente, tornando o trabalho criativo e prazeroso.

A abordagem transdisciplinar pressupõe a utilização de diversas linguagens na educação, de modo a facilitar a aprendizagem. Considerando que há vários tipos de inteligências, hábitos, comportamentos, dificuldades, valores, normas entre os integrantes do grupo, a sala de aula tornou-se espaço propício para desenvolvermos atividades e metodologias diversas a fim de atingir o maior número de estudantes. Por exemplo, há aqueles com maior facilidade de apreensão das informações com linguagem auditiva. Para esses, ouvir o conteúdo é essencial; mas também poderia ter sido uma aula expo-

3. A Declaração Universal de Direitos Humanos está disponível na Internet em: <http://www.mj.gov.br/sedh/ct/legis_intern/ddh_ bib_inter_universal.htm>. Acesso em: 26 mai. 2011. 
sitiva, certamente um bom recurso; outros, cuja memória é estimulada com recursos visuais, depositam na atividade visual especial atenção. Outra forma de atuação poderia ser uma dramatização, um recurso enriquecedor.

As oficinas, além de apresentarem as reflexões desenvolvidas com a leitura da carta 23, ao serem associadas aos artigos da DUDH com o apoio nas artes, possibilitaram trabalhar as dimensões sensível, afetiva, estética e corporal entre os sujeitos. Os estudantes foram capazes de participar de trabalhos em grupo e refletiram criticamente sobre o material proposto, sobre a sua própria prática e suas ações.

Após as apresentações das oficinas, houve uma plenária geral, na qual os estudantes relataram:

Nunca havia percebido a dor do outro, a oficina de teatro me colocou neste lugar. Faltamme palavras para expressar a angústia que nos invade o peito diante da expressão de tanta dor [...]. Talvez as palavras não dêem conta de expressar nossa tristeza e indignação! (sujeito 4)

[...] é inconcebível que essas coisas aconteçam em qualquer sociedade. As pessoas têm dificuldade em lidar com o melhor do ser humano que é ser um "ser humano" [...] precisamos militar em prol dos direitos humanos sempre. Talvez a Educação em Direitos Humanos ajude em curto prazo a tornarmo-nos seres mais sensíveis e afetivos [...] (sujeito 45)

Após a oficina de canto, na qual o meu grupo escolheu a música "vida de gado" do Zé Ramalho, percebo que estamos patinando no vício do ruim, patinamos na ideia da possibilidade de uma desconstrução do sistema, mas sempre nos adequamos. Será comodismo? Por que não instituímos o PNEDH? A sociedade não seria melhor? Os sujeitos nãos seriam mais sensíveis e assim atentos às desigualdades sociais? (sujeito 3)

A lógica complexa e transdisciplinar indica que podem ser traçados novos rumos para uma mudança paradigmática nos contextos formativos. A ideia centra-se no conviver coletivo solidário e cooperativo, e, na sala de aula, implica em simples ações como chamar pelo nome, mostrar que as pessoas estão sendo vistas, que têm visibilidade no grupo, que têm voz, são passíveis de ações transformadoras e respeitabilidade. Desse modo, dar oportunidade para que as pessoas se expressem, por exemplo, possibilitalhes a discriminação mais clara dos limites de sua autonomia e de sua dependência das relações estabelecidas. Tal postura torna possível a busca de soluções a questões essenciais, como a luta por um ideal integrador e não-excludente e capaz de promover uma transformação profunda nos sujeitos.

Na perspectiva da formação acadêmica, a proposta pressupõe esforços no sentido de se promover uma mente ampliada que sustente uma consciência planetária. Assim, a pessoa será portadora de um olhar afetivo-sensível sobre si mesma, sobre as pessoas, a natureza, a vida. Os estudantes demonstraram isso. 
Para além da importância da presença da afetividade e da sensibilidade nos contextos formadores, o pensar complexo preocupa-se em refletir a respeito de fenômenos em que interagem muitos fatores, em que se combinam princípios de regulação e de desequilíbrio, em que comparecem contingência e determinismo, criação e destruição, ordem e desordem, em que podem ser identificados níveis de organização e dinâmicas não-lineares marcadas por retroações entre esses níveis. Por isso, para a complexidade e a transdisciplinaridade, o desenvolvimento da sensibilidade é proposto como dimensão originária e matricial, como matriz geradora do entendimento da condição humana.

De acordo com Araújo (2009), a sensibilidade passa a ser compreendida como

[...] um estado pregnante e anímico que emerge desde dentro, das nascentes do existir, que se traduz na radicalidade e na amplitude da disposição e da abertura existenciais para as transitudes do ser-sendo. Disposição que proporciona a compreensão e a vivência da inteireza do ser-sendo no dinamismo de suas intensidades e incompletudes. [...] a sensibilidade é concebida como estado de disposição do corpo e do espírito, [...] que, de modo coexistencial, nos conduzem à fruição do sentimento do mundo na expressão de sua vastidão incomensurável. A sensibilidade nos ajuda a perceber, sentir e fruir o estado de entrelaçamento que nos interliga com todos os seres do universo, mediante o elã da sinergia que nos interpenetra e que nos implica com a anima mundi (alma do mundo). Assim, podemos compartilhar a sutileza dos sentimentos que nos sinergizam com todos os seres do universo; podemos nos enredar na simpatia do todo. (Araújo, 2009, p. 204-205)

Nessa direção, Lowen assim se expressa:

A sensibilidade é a qualidade de uma pessoa que está plenamente viva [...]. A sensibilidade depende de uma tranqüilidade interior que decorre de uma ausência de luta ou esforço. Esses são os valores que conferem a vida um sentido verdadeiro, pois são as qualidades que promovem a alegria. (Lowen, 1997, p. 219)

Educar um sujeito sensível é educá-lo para a vida, para perceber a vida. Merleau Ponty (1984, p. 235) afirma que o sensível é a vida; "é um tesouro sempre cheio de coisas a dizer" na intensidade do existir.

Nesse horizonte compreensivo, Swimme (1991, p. 80) também indica que "o universo é sensível, é um reino de sensibilidade"; quanto mais exercitamos as potencialidades afetivas e sensíveis, mais e melhor podemos apreender, compreender, vivenciar e coexistir com a dinamicidade dos ritmos da vida.

Para a proposta transdisciplinar, o ser sensível amplia sua capacidade de percepção, de compreensão dos fenômenos em sua complexidade, por isso amplia-se a inteireza do seu existir. Isso pode ajudá-lo a despertar um estado de solicitude que o auxiliará na 
superação das posturas defensivas diante das dificuldades apresentadas pela vida. Essa superação gerará a atitude de abertura que convoca o sujeito por inteiro, de maneira integral, para processos intensivos de buscas de respostas.

Outro aspecto importante, de acordo com Araújo (2009), é o fato de que a abertura sensivel faz emergir processos admirantes de encantação. 0 estado de encantação provoca um viver de admiração das coisas; um espantar-se que aproxima o sujeito do vivido/vivente, das trajetórias humanas, compelindo-o a ultrapassar os estados de anestesiamento que comprimem o coração e a alma humanos. Vejamos as colocações dos estudantes:

[...] com esta atividade fui tocado no meu ponto fraco, adoro dança, participar da oficina de dança foi ótimo. Estou encantado. Minha oficina associou dança, beleza e leveza com a solidariedade. Aprendi que poderíamos através do corpo ressignificar as coisas fazendo com que a vida tenha mais sentido, prazer e dignidade [...] (sujeito 4)

[...] nunca me imaginei trabalhando o corpo. Nunca trabalhei o corpo dos meus alunos. Achei fantástica a oficina. Aprendi que quem educa, educa o corpo do outro [...] adorei, mas ver os colegas se esforçando na elaboração das oficinas foi o melhor, aprendi muito e desenvolvi o desejo de superar minhas dificuldades, assim como promover esse entendimento em meus alunos. Gostaria de torná-los sensíveis a vida [...] (sujeito 48)

Esse estado de profunda admiração pela vida resulta em despojamento e disponibilidade do espírito que levam o sujeito a superar os próprios limites e possibilidades existenciais, fragilidades e forças, incompletudes, tornando-o apto a identificar suas próprias insensibilidades.

Assim, ao tornar-se um sujeito sensível, não poderá ficar indiferente às dificuldades apresentadas pelo nosso mundo contemporâneo. 0 sujeito passa de um estado de anestesiamento para um estado compreensivo, dinâmico, complexo, com um senso fino que o conduz ao "espirit de finesse, espírito de fineza" (Araújo, 2009, p. 206).

Este espírito aguça o

senso perspicaz de discernimento e de compreensão da constituição heterogênea dos fenômenos e do existir; fomenta o senso espirituoso e afetivo que, ao compreender, se implica e se coimplica com o existir e com as coisas, com os fenômenos e os seres, com cordialidade e simpatia, com desprendimento e generosidade. Proporciona o cultivo do bom sentimento do mundo. (Araújo, 2009, p. 206)

O espirit de finesse faz com que o sujeito compreenda seu estado de pertencimento coletivo, planetário, ele passa a ser portador de uma ecosensibilidade, ou seja, uma sensibilidade ecológica/ecossistêmica que o faz compreender a composição do dinamismo 
da rede que entrelaça todos os seres, e que pode, por isso, levá-lo a posturas que afirmam essa cosmovisão (Moraes, 2003; 2004).

Precisamos de parâmetros que possam nos auxiliar, tanto a elaboração de políticas públicas mais consistentes que sejam capazes de gerar práticas sociais que impeçam essas posturas apresentadas na carta 23 , e que gerem ações mais comprometidas com a responsabilidade social [...] Se somos seres reflexivos, criativos, afetivos e sensíveis 0 suficiente para apresentar em forma de oficinas o que elaboramos em nosso interior, também o somos para implementar novas formas de ser no mundo, de entender a condição humana [...] (sujeito 31)

De igual modo, o educador transdisciplinar mobiliza um aprendizado coimplicado, com base numa ação viva, tecida de forma teórica e vivencial, capaz de reafirmar processos de renovação constante da afetividade e da sensibilidade humana.

Para tanto, a proposta educacional transdisciplinar sugere a articulação de saberes/ conteúdos através de pontos de interseção entre as ciências da ciência, entre as ciências e as artes, entre a filosofia e as ciências, entre as tradições espirituais, entre o saber do senso comum e o erudito. E mais, os repertórios culturais devem ser, conjuntamente, de forma simultânea e alternada, associados por experiências vivenciais, como o proposto nas oficinas pedagógicas. Assim somam-se aos saberes momentos e processos de fruição cotidianos, nos quais o corpo e o espírito estão presentes com toda intensidade.

0 cuidado com o desenvolvimento da sensibilidade também gesta a percepção intuitiva, e esta possibilita um novo entendimento das ações, dos gestos, dos movimentos difusos, dos silêncios, dos humores, amores e dissabores. Capta atitudes e fenômenos que escapam ao senso lógico-formal tido como aparentemente insignificantes, mas que são bastante relevantes para a ação de educar na perspectiva da escuta sensível, do senso compreensivo, cooperação, simpatia e empatia.

Ao tecer saberes levando-se em consideração a importância da sensibilidade e da afetividade, indicamos a possibilidade de novas sabedorias serem incorporadas às vivências cotidianas, e com elas é possível auxiliar o ser humano a apreender e compreender de forma mais intensa aquilo que está na vida por inteiro. Um humano afetivosensível tem condições de redescobrir, reinventar caminhos mais humanos e mais verdadeiros (Gadotti, 2007)

Devemos ser militantes em prol dos Direitos Humanos, pois precisamos de experiências de conciliação, cooperativas e solidárias. Experiências pautadas na sensibilidade, na afetividade, no princípio ético, acima dos interesses pessoais, próximas do bem comum e da manutenção da vida [...] (sujeito 17). 
Paulo Freire estava certo: o trabalho de educação é antes de tudo um ato de amor, presente em cada palavra, em cada gesto, em cada realização. EDH pode ter essa expressão [...] (sujeito 19)

No contexto da formação docente, esta proposta auxiliaria na superação de processos mecanizados de transmissão dos saberes. Educaríamos um sujeito capaz de criar um saber que confronta valores, ideais, convicções, crenças, sempre numa postura aberta, disponível a acrescentar o novo; a transgredir, incorporar modelos e sistemas cada vez mais interligados, mais fecundos energética e transdisciplinarmente.

Conforme Delors (2000), o movimento transdisciplinar ensaiou alguns passos no livro Educação: Um Tesouro a Descobrir, com a exposição dos pilares da educação do século XXI: Aprender a conhecer - a educação tem a finalidade promover o prazer de compreender, de conhecer e de descobrir; Aprender a fazer - tem maior referência com a formação profissional; o indivíduo aprende e põe em prática os seus conhecimentos; Aprender a viver juntos e Aprender a ser - indicam a necessidade de se aprender a viver com os outros, desenvolver a compreensão das interdependências; trabalhar a participação em projetos comuns, nos valores do pluralismo e da compreensão mútua de paz. Esses pilares edificam um educar transdisciplinar.

Da mesma forma, no livro Os sete saberes necessários a educação do futuro, Morin (2000) apresenta diversos pontos de vista sobre o processo educacional: o epistemológico, o pedagógico, o ético e o político; sua tese apresenta alguns eixos que devem ser superados por aqueles interessados em pensar e fazer educação e que estão preocupados com o futuro que está tomando nossas sociedades. Neste livro, são traçados os fios visíveis que conformarão a educação do futuro; a formação docente, por conseguinte, não pode perder de vista esses parâmetros, sob risco de se manter retrógrada em relação ao cenário educacional nacional e até mundial. Como afirma Morin (2000), estamos unidos, partilhando um saber que não se imagina separado, e essa postura perpassa e ultrapassa o campo interdisciplinar, para reconhecer os diferentes níveis de realidade e criar espaços de diálogos multirreferenciais com as diversas culturas, com a vida de cada grupo humano.

0 educar transdisciplinar, além de abrir possibilidades de visões plurais a respeito de um fenômeno ou conceito (Morin, 1999; 2000; 2002), (re)cria espaços de afetividade, de amor, de sensibilidades, possibilitando uma práxis pedagógica que se configura na arte de aprender. Portanto, cria um educar preocupado com o desenvolvimento de um ser plural, capaz do exercício da flexibilidade, criticidade, criatividade, o que o possibilita a vazão de um amplo espectro de referenciais capazes de promover uma travessia do eu para o nós (Freire, 1997; 2000; Bordas, 1999). 
Na proposta de Pineau (1999), estamos diante de processos intensivos de autoeducação, heteroeducação e de ecoeducação, que tornam o sujeito um ser sensível e afetivo. Afinal, ao aprender a tecer os fios da autoeducação mediante as aprendências coletivas com os outros seres humanos, reestruturam-se novas formas de se pensar, pois o educar passa a ser vivido enquanto vida pulsante, que se constrói com o individual e o coletivo, inserido neste planeta, viabilizando-se, então, o canal de encontro do amor e da vida - consciência amorosa.

Com uma consciência amorosa, como afirma Morin (2002), o sujeito terá a capacidade de auto-organizar-se, transcender; promover o cuidado com o advento dos valores humanos, suscitando entrelaces que o aproximam e que o compelem à ecofraternização. Entretanto, a formação de uma consciência amorosa só se faz possível se o amor for compreendido como princípio educativo, aquele que potencializa o desabrochar da sensibilidade humana, e propicia o cultivo dos valores que enobrecem. Dessa forma, podemos projetar ambientes, relações e ações educativas estimuladoras e aprazíveis; instalar entre-lugares educativos em que a simpatia e a empatia sejam capazes de criar ritos de iniciação às apreendências da afetividade e sensibilidade humanas.

Uma formação preocupada com processos formativos que deem ênfase ao afetar e ao sensibilizar humanos promove a constituição de uma razão-afetivo-sensível, e com ela o futuro professor e a futura professora poderão: assumir conscientemente a intencionalidade de sua prática como mediação afetiva; procurar conhecer suas possibilidades, limitações, pontos fortes, suas motivações, valores e sentimentos, bem como de seus estudantes, para que a sua ação pedagógica seja sinergética, ou seja, entre pólos que se harmonizam complementar e holisticamente, de forma aberta e contínua.

Esse modo de proceder cria, então, a possibilidade de escolhas mais adequadas nas diferentes situações pedagógicas, além de auxiliar o professor a reconhecer e assumir com clareza valores que dirijam as suas decisões e escolhas no campo pedagógico. Este professor terá ações reais, significativas, e isso significa que ele estará centrado em si mesmo e no outro, em equilíbrio nas direções para dentro (conhecimento de si) e para fora (conhecimento do mundo), com maiores recursos para controle das emoções e dos sentimentos, e para colaborar na resolução qualitativa dos conflitos.

Cremos que a formação docente pode conduzir o futuro professor a um viver formador que estabeleça uma razão-afetivo-sensível, com vistas a promover uma visão mais integrada do ser humano, marcando, definitivamente, a relação do sujeito com o objeto de conhecimento, e deste com a própria vida. 


\section{Referências}

ALMEIDA, Ana Rita Silva. A emoção e o professor: um estudo à luz da teoria de Henri Wallon. Psicologia: Teoria e Pesquisa. Brasília, v. 13, n. 2, p. 239-249, mai./ago. 1997.

ARAÚJO, Miguel Almir Lima de. Os sentidos da sensibilidade e sua fruição no fenômeno do educar. Educação em Revista. [online]. 2009, v. 25, n. 2, p. 199-221. Disponível em: < http://www.scielo.br/ scielo.php?script=sci_arttext\&pid=S0102-46982009000200009\&lng=pt\&nrm=iso >. Acesso em: 26 maio 2011. ASSMANN, Hugo. Reencantar a Educação: rumo à sociedade aprendente. Petrópolis: Vozes, 1998. BARTHES, Roland. A preparação do romance l: da vida à obra. São Paulo: Martins Fontes, 2005. BORDAS, Miguel Angel Garcia. 0 processo educacional, a comunicação e os agentes duplos: elementos para uma teoria da ação educativa em base semiótica. Revista Ágere, Salvador: v.1, p. 88-105, 1999. BOGDAN, Robert; BIKLEN, Sari. Investigação qualitativa em educação. Porto: Porto, 1994.

BRANDÃO, Carlos Rodrigues. Aprender o amor: sobre um afeto que se ensina a viver. São Paulo: Papirus, 2005.

. Humanizar é educar: o desafio de formar pessoas através da educação. Escritos abreviados. Portal Educacional do Estado do Paraná, n. 3, 2008. (Série cultura/educação)

BRASIL. Comitê Nacional de Educação em Direitos Humanos. Plano Nacional de Educação em Direitos Humanos/Comitê Nacional de Educação em Direitos Humanos. Brasília: Secretaria Especial dos Direitos Humanos, Ministério da Educação, Ministério da Justiça, UNESCO, 2008. Disponível em: <http://www.mj.gov.br/sedh/edh/pnedhpor.pdf>. Acesso em: 26 maio 2011.

CANDAU, Vera Maria et al. Oficinas Pedagógicas de Direitos Humanos. Petrópolis: Vozes, 1995.

CODO, Wanderley; GAZZOTTI, Andréia Alessandra. Trabalho e afetividade. In: CODO, Wanderley. Educação: carinho e trabalho. Petrópolis: Vozes/Brasília CNTE e Brasília LPT, 1999.

CHIZZOTTI, Antonio. Pesquisa em Ciências Humanas e Sociais. São Paulo: Cortez, 2003.

DANTAS, Heloysa. Afetividade e a construção do sujeito na psicogenética de Wallon. In: LA TAILLE, Yves de; DANTAS, Heloisa; OLIVEIRA, Marta Kohl. Piaget, Vygotsky e Wallon: teorias psicogenéticas em discussão. São Paulo: Summus, 1992.

Emoção e ação pedagógica na infância: contribuição de Wallon. Temas em Psicologia. Sociedade Brasileira de Psicologia, São Paulo, v. 1, n. 3, p. 73-76, dez. 1993.

DELEUZE, Gilles. Francis Bacon: lógica da sensação. Rio de Janeiro: Zahar, 2007.

DELORS, Jaques. Educação: um tesouro a descobrir. São Paulo: Cortez, 2000.

FERNANDÉZ, Alicia. A inteligência aprisionada. Porto Alegre: Artes Médicas, 1991.

FREIRE, Paulo. A educação do futuro. Jornal O Globo. Rio de Janeiro, 24 maio 1997, Caderno Prosa \& Verso. Pedagogia da autonomia: saberes necessários à prática educativa. 15. ed. São Paulo: Paz e Terra, 1996.

GADOTTI, Moacir. Educar para um outro mundo possível. São Paulo: Publisher Brasil, 2007.

GROTTA, Ellen Cristina Baptistella. Processo de formação do leitor: relato e análise de quatro histórias de vida. 2000. Dissertação (Mestrado em Educação), Unicamp, Campinas, 2000.

JAPIASSÚ, Hilton; MARCONDES, Danilo. Dicionário Básico de Filosofia. 3. ed. Rio de Janeiro: Jorge Zahar, 2001. 
LEITE, Sérgio Antonio da Silva; TASSONI, Elvira Cristina Martins. A afetividade em sala de aula: as condições de ensino e a mediação do professor. Disponível em: < http://www.fe.unicamp.br/alle/ textos/SASL-AAfetividadeemSaladeAula.pdf>. Acesso em: 26 maio 2011.

LUCKESI, Cipriano Carlos. Avaliação educacional escolar: para além do autoritarismo. Tecnologia Educacional, Rio de Janeiro, n. 61, p. 6-15, nov./dez., 1984.

LOWEN, Alexander. Alegria: a entrega ao corpo e à vida. São Paulo: Summus, 1997.

MAHONEY, Abigail Alvarenga; ALMEIDA, Laurinda Ramalho de. Emoção e ação pedagógica na infância: contribuições da psicologia humanista. Temas em Psicologia, Sociedade Brasileira de Psicologia, São Paulo, n. 3, p. 67-72, 1993.

Afetividade e processo ensino-aprendizagem: contribuições de Henri Wallon. Psicologia da Educação, São Paulo, n. 20, jan./jun., 2005.

MERLEAU-PONTY, Maurice. O visível e o invisível. São Paulo: Perspectiva, 1984.

MORAES, Maria Cândida. Educar na biologia do amor e da solidariedade. Petrópolis: Vozes, 2003.

Vozes, 2004.

O pensamento eco-sistêmico: educação, aprendizagem e cidadania no século XXI. Petrópolis:

MORIN, Edgar. Complexidade e transdisciplinaridade: a reforma da universidade e do ensino fundamental. Natal: EdufRN, 1999.

. A cabeça bem-feita: repensar a reforma, reformar o pensamento. 7. ed. Rio de Janeiro: Bertrand Brasil, 2002.

Introdução ao pensamento complexo. Lisboa: Instituto Piaget, 1991.

. O Método. As Ideias. Tradução de Juremir Machado da. Silva. Porto Alegre: Sulina, 2008. v. 4.

Os sete saberes necessários à educação do futuro. Tradução de Catarina Eleonora F. da Silva e Jeanne Sawaya; revisão técnica de Edgard de Assis Carvalho. 2. ed. São Paulo: Cortez; Brasília: UNESCO, 2000. NICOLESCU, Basarab. O Manifesto da Transdisciplinaridade. São Paulo: Trion, 2001.

PEREIRA, Maria Izabel Galvão Gomes. Emoções e conflitos: análise da dinâmica das interações numa classe de educação infantil. 1998. Tese (Doutorado em Educação), Universidade de São Paulo, São Paulo, 1998.

PINEAU, Gaston. A autoformação no decurso da vida. Disponível em: <http://www.cetrans.futuro.usp.br /pineau.htm>. Acesso em 30 set. 1999.

PINO, Angel. As marcas do humano: às origens da constituição cultural da criança na perspectiva de Lev S. Vigotski. São Paulo: Cortez, 2005.

PRIGOGINE, Ilya; STENGERS, Isabelle. A Nova Aliança: A Metamorfose da Ciência. Tradução de Miguel, Faria e Maria, Joaquina Machado Trincheira. Brasília: Editora da UnB, 1997.

SANTOS, Boaventura de Souza. Um discurso sobre as ciências. Porto: Afrontamento, 1987.

SILVA, Vera Lucia de Souza. Educar para a conexão: uma visão transdisciplinar de educação para saúde integral. Blumenau: Nova Letra, 2004.

SNYDERS, Georges. Alunos felizes. São Paulo: Paz e terra, 1993.

SOUZA, Ruth Catarina; MAGALHÃES, Solange Martins; GUIMARÃES, Valter Soares. Sindicalização docente na produção acadêmica da Região Centro-Oeste. In: SEMINÁRIO PARA DISCUSSÃO DE PESQUISAS E CONSTITUIÇÃO DE REDE DE PESQUISADORES, 9., 2009. Rio de Janeiro, Anais... Rio de Janeiro: IUPERJ/UFRJ/UnB, 2009a. p. 1-11. Disponível em: <http://nupet.iuperj.br/rede/seminario2009.htm>. Acesso em: 26 maio 2011. 
. O professor na literatura contemporânea - ausência ou presença alheada? In: REUNIÃO ANUAL DA ANPED, 32., 2009. Caxambu, Anais... Caxambu: 2009b.

A questão metodológica: métodos e tipos de pesquisa na produção acadêmica sobre professores (as) na região centro-oeste. SEMEDU Seminário Educação, 2010. Cuiabá, Anais... Cuiabá: Universidade Federal de Mato Grosso, 2010.

SWIMME, Brian. $O$ universo é um dragão verde. São Paulo: Cultrix, 1991.

TASSONI, Elvira Cristina Martins. Afetividade e produção escrita: a mediação do professor em sala de aula. 2000. Dissertação (Mestrado em Educação), UNICAMP, Campinas, 2000. Disponível em: <http://www.bibliotecadigital.unicamp.br/document/?code=vtls000195521 >. Acesso em: 26 maio 2011.

TRIVIÑOS, Augusto Nibaldo Silva. Introdução a Pesquisa em Ciências Sociais: a pesquisa qualitativa em educação. São Paulo: Atlas, 1987.

VYGOTSKY, Lev Semyonovich. A formação social da mente: o desenvolvimento dos processos psicológicos superiores. São Paulo: Martins Fontes, 1998.

WALLON, Henri. As origens do caráter na criança. São Paulo: Difusão Européia do Livro, 1971.

. Do acto ao pensamento. Lisboa: Moraes Editores, 1978.

Psicologia e educação da infância. Lisboa: Estampa, 1995.

$1{ }^{\text {a }}$ versão recebida em julho de 2010

$2^{\mathrm{a}}$ versão aprovada em abril de 2011

Solange Martins Oliveira Magalhães. Psicóloga, Mestre e Doutora em Educação pela Universidade Federal de Goiás. Professora Adjunta da Faculdade de Educação e do Programa de Pós-Graduação em Educação da Universidade Federal de Goiás. Associada à Escola da Complexidade www.complexidade. ning.com. E-mail: solufglahotmail.com. 


\section{Linhas Críticas}

A revista foi criada em 1995 com o objetivo de divulgar a produção científica de docentes e pesquisadores da Faculdade de Educação da Universidade de Brasília, como também editar artigos de autores de outros centros de investigação do Brasil e do exterior. Conta, desde o início, com um Comitê e Conselho Editorial qualificado, reconhecido nacional e internacionalmente.

Ao longo desses anos publicou 32 números com um total de 287 artigos escritos por 365 pesquisadores oriundos de 15 países: Alemanha, Argentina, Brasil, Canadá, Cuba, Espanha, Estados Unidos, França, Israel, Itália, México, Portugal, Rússia, Timor-Leste e Uruguai.

\section{NÚMEROS TEMÁTICOS}

No. 32 (vol. 17) Docência, formação e gestão

No. 31 (vol. 16) Hermenêutica, teoria crítica e educação

No. 30 (vol. 16) Educação profissional e tecnológica

No. 29 (vol. 15) Formação de profissionais da educação

No. 28 (vol. 15) Políticas educacionais e novas formas de regulação

No. 26 (vol. 14) Docência na educação superior

No. 24 (vol. 13) Educação e novas tecnologias

No. 22 (vol. 12) Educação, formação e aprendizagem

No. 21 (vol. 11) Edição comemorativa: 10 anos de Linhas Críticas

No. 20 (vol. 11) Políticas públicas para a educação

No. 18 (vol. 10) Gestão na educação

No. 17 (vol. 9) Novas tecnologias na educação

No. 16 (vol. 9) Educação especial

No. 15 (vol. 8) Criatividade na educação

No. 12 (vol. 7) Formação de professores e financiamento da educação

No. 7-8 ( vol. 4) Psicodrama na educação

No. 5-6 (vol. 3) Filosofia para crianças

No. 3-4 (vol. 2) Faculdade de Educação da UnB: um ideário pedagógico à altura do Brasil 